\title{
CLINICAL PATHOLOGICAL REVIEW
}

DAVID APPLE AND MILTON BONIUK, EDITORS

\section{Invasive Squamous Cell Carcinoma of the Conjunctiva Presenting as Necrotizing Scleritis with Scleral Perforation and Uveal Prolapse}

\author{
KIM A. LINDENMUTH, M.D., ${ }^{1}$ ALAN SUGAR, M.D., ${ }^{1}$ MARILYN C. KINCAID, M.D., ${ }^{1,2}$ \\ GHRISTINE C. NELSON, M.D., ${ }^{1}$ AND CHRISTOPHER P. COMSTOCK, B.S. ${ }^{1}$
}

\author{
W.K. Kellogg Eye Center, Departments of ${ }^{7}$ Ophthalmology and ${ }^{2}$ Pathology, University of Michigan, Ann \\ Arbor, Michigan
}

\begin{abstract}
A 64-year-old white man presented with necrotizing scleritis with scleral perforation and uveal prolapse. Pathologic examination revealed squamous cell carcinoma of the conjunctiva invading adjacent corneal stroma and ciliary body. Invasive squamous cell carcinoma of the conjunctiva is uncommon, and intraocular invasion has rarely been reported in the literature. (Surv Ophthalmol 33:50-54, 1988)
\end{abstract}

Key words. conjunctiva - ocular invasion - scleritis - squamous cell carcinoma

A 64-year-old white man presented to the cornea service with a three-day history of photophobia, tearing, pain, redness, and decreased vision in the left eye. His past ocular history was significant for the biopsy of a limbal conjunctival lesion one year prior to presentation. Histologically, this had shown elastoid degeneration. Since that time, he reported intermittent episodes of ocular irritation. There was no history of tuberculosis, syphilis, rheumatologic disease, or any other systemic illness.

On examination, his best corrected visual acuity was 20/20 OD and 20/300 OS. The right eye was entirely normal. The left eye was markedly injected. There was a $4 \mathrm{~mm}$ by $4 \mathrm{~mm}$ area of iris prolapse through a limbal scleral perforation at the 4 o'clock position. Superior to the perforation was a $2 \mathrm{~mm}$ by $4 \mathrm{~mm}$ area of necrotic perilimbal sclera which appeared avascular and thin. Posterior to the area of uveal prolapse was a $7 \mathrm{~mm}$ by $7 \mathrm{~mm}$ area of markedly thickened and inflamed sclera (Fig. 1). Corneal sensation was normal. There were $1+$ pigmented cells on the inferior endothelial surface of the cornea. The anterior chamber was deep and demonstrated $3+$ cells and flare. The iris was peaked toward 4 o'clock and prolapsed through the limbal perforation. The cornea itself appeared intact and Seidel test was negative. Tensions by applanation were 18 in each eye. Schirmer test results were $5 \mathrm{~mm}$ $\mathrm{OD}$ and $0 \mathrm{~mm} \mathrm{OS}$ at five minutes with anesthetic. There were $2+$ nuclear sclerotic lens changes. Fun- 
duscopic examination was unremarkable.

The initial impression was scleral necrosis with perforation and uveal prolapse. The underlying etiology was unclear but appeared to be an acute necrotizing scleritis. The patient was admitted for further evaluation and treatment. He was started on topical prednisolone acetate $1 \%$, tobramycin, cyclopentolate $1 \%$, and indomethacin.

A gram stain and culture from the inflamed site were negative. A PPD was negative. Chest $x$-ray, complete blood count, electrolytes, rheumatoid Factor, C3, C4, total hemolytic complement, antinuclear antibody, and Westergren sedimentation rate were all within normal limits.

Over the next 36 hours, the patient showed progressive scleral thinning and necrosis. He was taken to the operating room where a scleral patch graft was placed. The inferior rectus muscle appeared to be infiltrated with inflammatory tissue. A specimen was sent for pathologic and microbiologic examination.

The pathologic diagnosis was squamous cell carcinoma of the conjunctiva with tumor involvement of all margins. Because of the invasive nature of the tumor causing rupture of the globe along with probable infiltration of the orbital soft tissues, an exenteration was performed.

Physical examination by internal medicine and otolaryngology specialists did not reveal any evidence of metastatic involvement. One year after the exenteration, there is no evidence of recurrence or metastatic disease

\section{Pathologic Findings}

The exenteration specimen consisted of the eyelids, globe, and orbital tissue. The scleral patch graft was identified anteriorly at the 4 o'clock position. The eye was sectioned horizontally after the eyelids had been removed and separately submitted.

Microscopic evaluation of the eye revealed a thin, but normal corneal epithelium. The corneal stroma was swollen and Descemet's membrane was continuous. The chamber angle was closed on the side of the neoplastic invasion, but it was open nasally. The patch graft was noted on the temporal aspect, extending from peripheral cornea to lateral rectus muscle (Fig. 2). The invading squamous cell carcinoma involved the angle and covered a portion of the peripheral iris and ciliary body (Fig. 3) and also invaded corneal stroma for a short distance (Fig. 4). Islands of epithelial neoplasm were recognized on the outer surface of the patch graft. The retina and optic nerve were normal.

The epithelial neoplasm demonstrated a disturbance in maturation with cellular disorganization.

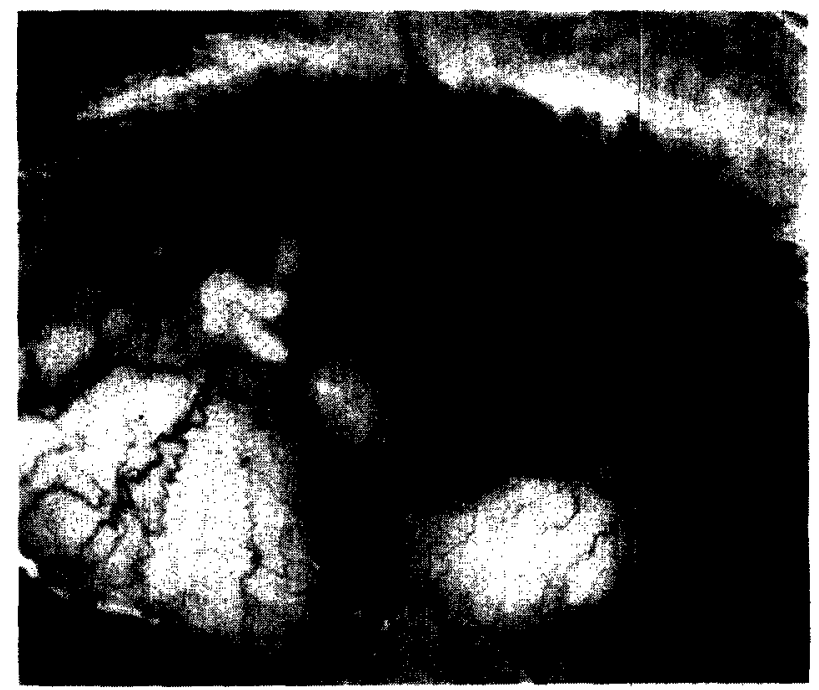

Fig. 1. Uveal prolapse through the scleral perforation. Superior to the perforation is an area of thin, avascular sclera (asterisk). Inferiorly, the sclera is markedly thickened and inflamed.

There were small spindle cells with eosinophilic cytoplasm, and oval nuclei which lacked a prominent nucleolus. There were also larger epithelial cells with a large nucleus and prominent nucleolus. There was no distinct border between the neoplastic cells and the normal conjunctiva in the original biopsy.

\section{Discussion}

Our case of invasive squamous cell carcinoma had an unusual presentation of necrotizing scleritis with scleral perforation and uveal prolapse. Stokes ${ }^{15}$ reported the case of a 78-year-old man who had a squamous cell carcinoma of the conjunctiva removed, but tumor cells extended to the margins of the excision. He went on to develop iritis and what was thought to be a luetic scleritis. The conjunctival mass did not recur. Nine months after the tumor was removed, he developed a scleral perforation. Examination of the globe revealed squamous cell carcinoma invading the iris, ciliary body, suprachoroidal space, and choroid. Although, unlike our case, scleritis was not the presenting finding, this is the only other case to our knowledge in which intraocular invasion of conjunctival squamous cell carcinoma masqueraded as necrotizing scleritis.

Invasive squamous cell carcinoma of the conjunctiva is uncommon, and intraocular invasion has rarely been reported in the literature. It must be distinguished from intraepithelial epithelioma, sometimes referred to as Bowen's disease, ' carcinoma-in-situ, ${ }^{19}$ or conjunctival intraepithelial neopla- 


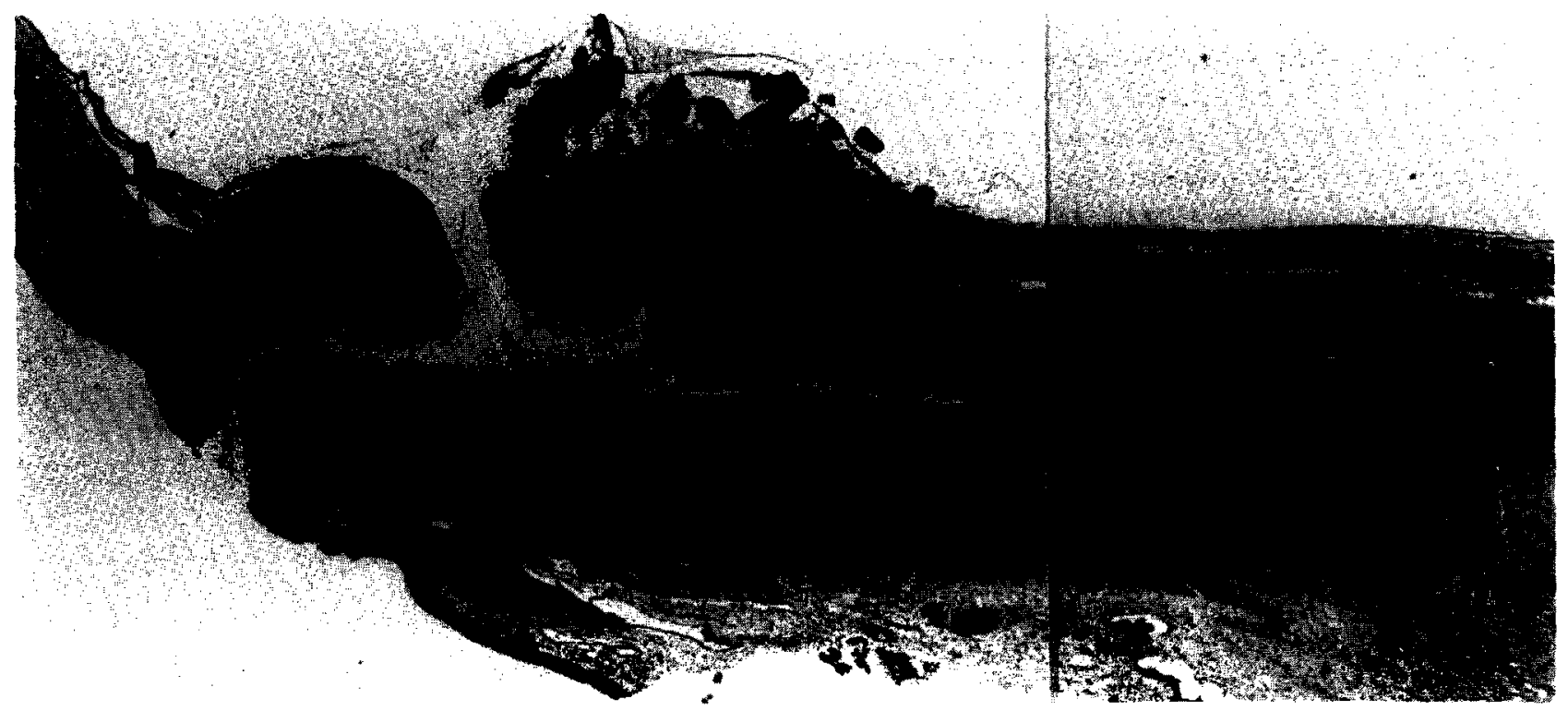

Fig. 2. A low-power view demonstrates the scleral patch graft, which extends from the cornea posteriorly (arrowheads). Squamous cell carcinoma invades the plane between the sclera and the scleral patch graft, the cornea, and the ciliary body (asterisks). (Hematoxylin \& Eosin, $x$ 15)

sia. ${ }^{12}$ These lesions are characterized by proliferation of atypical squamous cells with a distinct border between normal and abnormal epithelium and no invasion through the conjunctival basement membrane. ${ }^{\prime}$

Infiltration of atypical epithelial cells through the basement membrane defines invasive squamous cell carcinoma of the conjunctiva. These tumors usually arise at the corneoscleral limbus and present clinically as a white, smooth, vascularized, slightly to moderately elevated mass with a gelatinous appearing extension onto the cornea ${ }^{4,9}$ Extension on to the cornea is frequently accompanied by the development of painful keratitis and iriducyclitis. ${ }^{2,11} \mathrm{Tu}$ mors away from the limbus are uncommon and should raise suspicion of an association with sebaceous gland carcinoma of the eyelid. ${ }^{18}$

François et al ${ }^{5}$ reviewed 49 cases of invasive squamous cell carcinoma of the conjunctiva. In his series, $72 \%$ invaded the cornea, $48 \%$ the sclera, $42 \%$ the angle structures, and $50 \%$ the iris and ciliary body. Twelve percent of the cases developed metastases. Greer, 'Stokes, ${ }^{15}$ Nicholson, ${ }^{11}$ Rasteiro ${ }^{3}$ and $\mathrm{Li}^{10}$ described a total of six cases with intraocular extension. Irvine ${ }^{9}$ reviewed 104 cases of limbal epithelial tumors. The basement membrane was invaded in 20 cases, but only one case had intraocular extension and none developed metastatic disease.

Zimmerman ${ }^{19}$ followed 35 cases of invasive carcinoma of the conjunctiva for 5 to 30 years after simple excision of the tumor. Nine of the patients had recurrence with only one of them developing metastatic disease. $\mathrm{He}^{19}$ also reviewed 87 cases of conjunctival carcinoma, of which four patients developed metastatic disease. Apparently, none had intraocular extension. Iliff ${ }^{8}$ reviewed 27 cases of invasive squamous cell carcinoma. One developed intraocular extension and three showed orbital invasion. Two of these cases developed metastases. He reported a $36 \%$ recurrence rate after tumor excision.

Erie $^{4}$ reviewed 98 patients with conjunctival and corneal intraepithelial neoplasia (CIN) and 22 patients with invasive carcinoma. Nine of the invasive carcinoma patients developed recurrences. Metastatic disease developed in two patients who had evidence of orbital involvement. All nine of the recurrences had surgical margins involved in the initial excision. Two patients had evidence of intraocular involvement. Of the patients with CIN, 24\% (23) had a recurrence, with three of these showing invasion at the time of recurrence. The recurrence rate was $5 \%$ in the CIN lesions with frec surgical margins and $53 \%$ in the CIN lesions with the margins involved.

Although squamous cell carcinoma of the conjunctiva is the most frequently seen malignant neoplasm of the conjunctival epithelium, the literature suggests that it normally behaves in a nonaggressive fashion that seldom leads to intraocular invasion. However, a variant of this neoplasm, mucoepidermoid carcinoma, behaves much more aggressively 


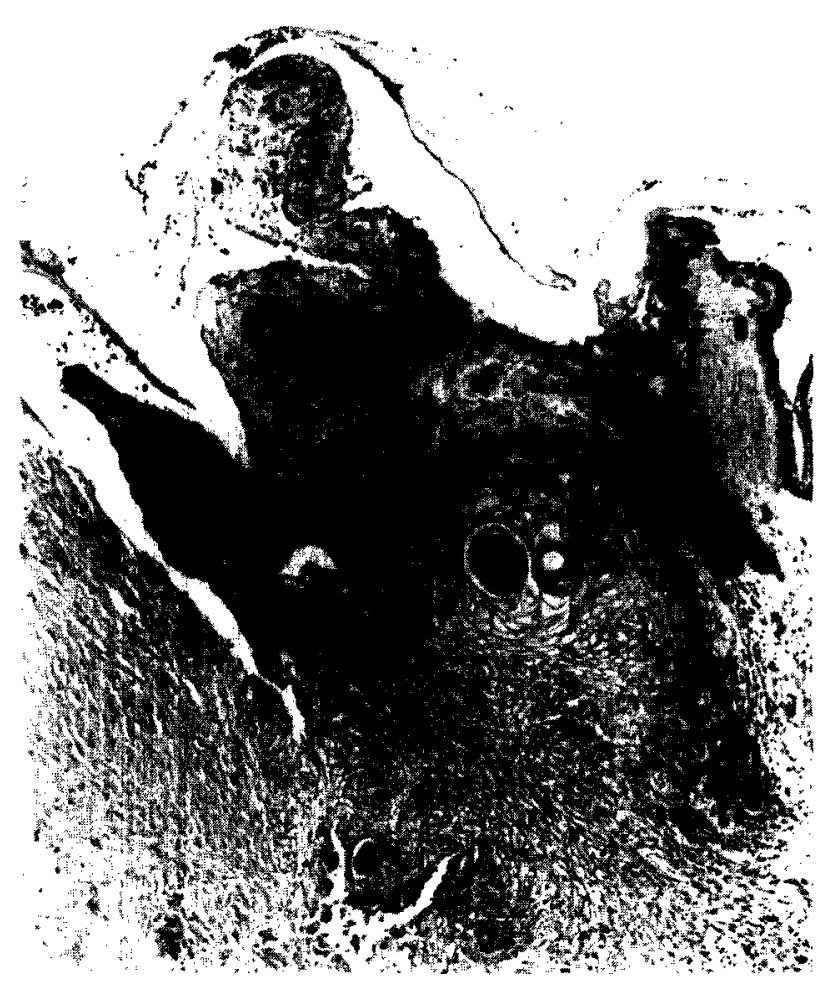

Fig. 3. The squamous cell carcinoma invades the ciliary body. (Hematoxylin \& Eosin, $x+40)$

and has a high capacity for intraocular invasion..$^{3.6 .14}$ Mucoepidermoid carcinoma occurs mainly in the major and minor salivary glands and rarely arises in the conjunctiva. It is characterized histologically by a variable composition of primarily mucus-producing cells, squamous cells, and intermediate basosquamous cells. Clinically, it is often indistinguishable from squamous cell carcinoma, and histopathologic examination with mucin stains (i.e., mucicarmine, PAS, and Alcian blue) is needed to facilitate making the diagnosis. It should be emphasized that the mucoid component of the tumor may only be apparent in the recurrent intraocular component, while the primary lesion displays the histologic features of typical squamous cell carcinoma, making early diagnosis of this variant difficult."

Wexler ${ }^{17}$ reported an uncharacteristically aggressive squamous cell carcinoma of the conjunctiva, which was not the mucoepidermoid type. The first appearance of the limbal lesion was followed six weeks later by evidence of intraocular extension.

François" recommended enucleation or evisceration followed by radiation treatment for the management of invasive squamous cell carcinoma. However, Irvine," Iliff ${ }^{\mathrm{P}}$ and Zimmerman ${ }^{20}$ stated

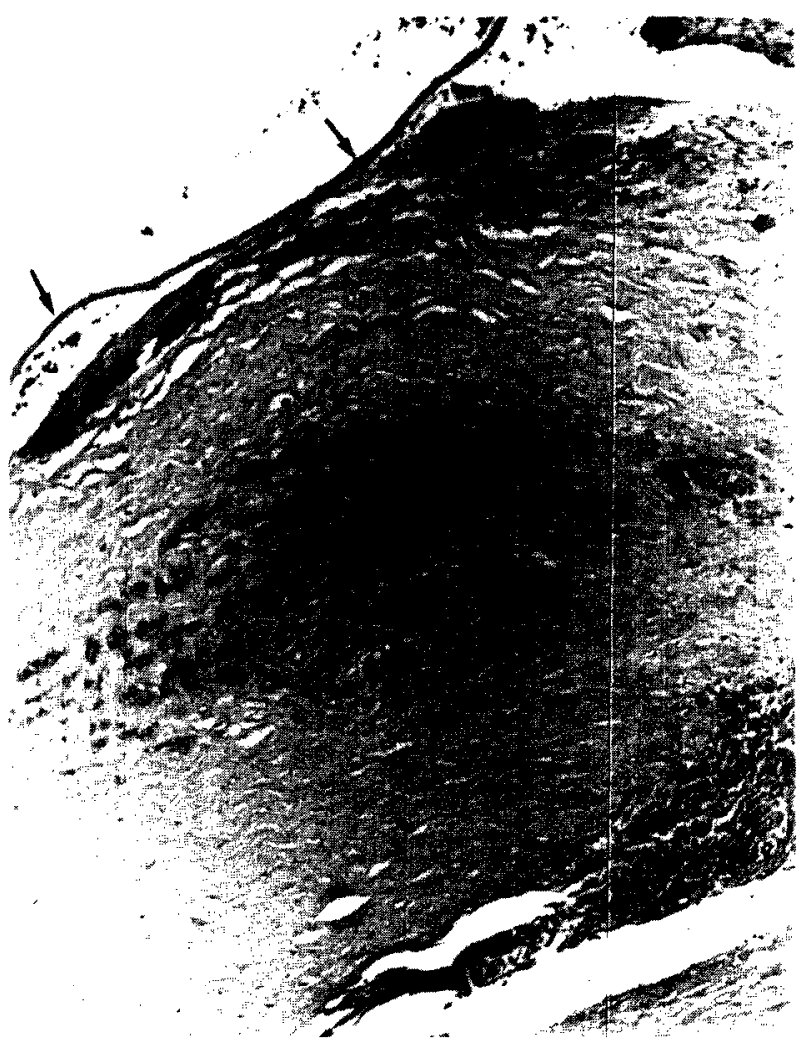

Fig. . The squamous cell carcinoma invades the corneal stroma (arrowheads indicate Descemet's membrane) (Hematoxylin \& Eosin, $\times 50$ )

that invasive squamous cell carcinoma of the conjunctiva is a low grade neoplasm which most commonly does well with local excision, but that the high recurrence rate warrants close follow-up. Erie's ${ }^{t}$ findings suggest that clean surgical margins improve the prognosis for CIN and possibly for conjunctival carcinoma.

$\mathrm{Li}^{\prime \prime \prime}$ suggested that invasive squamous cell carcinoma with intraocular extension might be treated with a wide en bloc resection of the conjunctival mass, cornea, sclera, iris, and ciliary body. Their two patients required enucleation after en bloc excision failed to give tumor free margins. Enucleation is the accepted treatment for intraocular extension of squamous cell carcinoma, ${ }^{8,111.114}$ with exenteration reported by some, ${ }^{2,8}$ particularly if orbital involvement is suspected. Our patient had evidence of orbital involvement with suspected tumor infiltration of the rectus muscles and orbital soft tissue; therefore, we elected to treat him aggressively with exenteration.

Our patient is unusual in two respects. First, he presented initially with what appeared to be necrotizing scleritis with scleral pcrforation and uveal prolapse. Necrotizing scleritis is more commonly 
associated with rheumatoid arthritis, systemic lupus erythematosus, polychondritis and periarteritis nodosa. ${ }^{16}$ To our knowledge, necrotizing scleritis as the presenting sign of squamous cell carcinoma has not been previously reported. Second, although this tumor was highly aggressive with intraocular extension, it did not belong to the more invasive variant of squamous cell carcinoma, mucoepidermoid carcinoma.

\section{References}

1. Apple DJ, Rabb MF: Ocular Pathology: Clinical Application and Self-assessment. St Louis, CV Mosby, 1985, ed 3, pp 444-486

2. Blodi FC: Squamous cell carcinoma of the conjunctiva. Doc Ophthalmol 34:94-108, 1973

3. Brownstein S: Mucoepidermoid carcinoma of the conjunctiva with intraocular invasion. Ophthalmology 88:1226-1229, 1981

4. Erie JC, Campbell J, Liesegang TJ: Conjunctival and corneal intraepithelial and invasive neoplasia. Ophthalmology 93:176183, 1986

5. François J, Hanssens M, German M: Epitheliomas perforantes du limbe et de la conjunctive bulbaire. Ann Ocul (Paris) 200:505521,1967

6. Gamel JW, Eiferman RA, Guibor P: Mucoepidermoid carcinoma of the conjunctiva. Arch Ophthalmol 102:730-731, 1984

7. Greer $\mathrm{CH}$ : Limbal epithelioma with intraocular invasion. $\mathrm{Br} J$ Ophthalmol 46:306-307, 1962

8. Iliff WS, Marback R, Green WR: Invasive squamous cell carcinoma of the conjunctiva. Arch Ophthalmol 93:119-122, 1975

9. Irvine AR Jr: Dyskeratotic epibulbar tumors. Trans Am Ophthalmol Soc 61:243 273, 1963

10. Li WW, Pettit TH, Zakka KA: Intraocular invasion by papillary squamous cell carcinoma of the conjunctiva. Am JOphthalmol 90:697-701, 1980
11. Nicholson DH, Hirschler J: Intrancular extension of squamous cell carcinoma of the conjunctiva. Arch Ophthalmol 95:843-846, 1977

12. Pizzarello LD, Jakobicc FA: Bowen's discasc of the conjunction: a misnomer, in Jakobiec FA (ed): Ocular and Adnexal Tumors. Birmingham, AL, Aesculapius, 1978, pp 553-571

13. Rasteiro A, Cunha-Vaz JG: Squamous cell carcinoma of the limbus with intraocular invasion. Ophthalmologica 172:332-336, 1976

14. Searl SS, Krigstein HJ, Albert DM, et al: Invasive squamous cell carcinoma with intraocular mucoepidermal features. Arch Ophthalmol 100:109-111, 1982

15. Stokes JJ: Intraocular extension of epibulbar squamous cell carcinoma of the limbus. Trans Am Acad Ophthalmol Otoloaryngol 59: $143-146,1955$

16. Watson P: Diseases of the sclera and episclera, in Duane $T$ (ed): Clinical Ophthalmology, Vol 4. Philadelphia, Harper and Row, 1983, Chapter 23, pp 1-39

17. Wexler SA, Wallow IHL: Squamous cell carcinoma of the conjunctiva presenting with intraocular extension. Arch Ophthalmol 193:1175-1177, 1985

18. Wolfe JT III, Yeatts RP, Wick MR et al: Sebaceous carcinoma of the eyelid; errors in clinical and pathologic diagnosis. $A m J$ Surg Pathol 8:597-606, 1984

19. Zimmerman LE: Squamous cell carcinoma and related lesions of the bulbar conjunctiva, in Boniuk M (ed): Ocular and Adnexal Tumors, St Louis, GV Mosby, 1964, pp 49-74

20. Zimmerman LE: The cancerous, precancerous, and pseudocancerous lesions of the cornea and conjunctiva: The Pocklington Memorial Lecture, in Rycraft PV (ed): Corneoplastic Surgery. New York, Pergamon Press, 1969, pp 547-555

Reprint requests should be addressed to Alan Sugar, M.D., Department of Ophthalmology, University of Michigan, W. K. Kellogg Eye Center, 1000 Wall Street, Ann Arbor, MI 48105-1994. 